\title{
剛性拧よび外力の不確定性を考慮したトラスの ロバストネス関数に対する近似アルゴリズム APPROXIMATION ALGORITHM FOR ROBUSTNESS FUNCTIONS OF TRUSSES
WITH UNCERTAIN STIFFNESS UNDER UNCERTAIN FORCES
}

\author{
寒野善博*1, 竹脇 出*2 \\ Yoshihiro KANNO and IzUru TAKEWAKI
}

\begin{abstract}
An approximation algorithm is presented for finding the lower bounds of robustness functions of linear elastic trusses associated with stress constraints. Under the uncertainties of member stiffness and external forces based on the info-gap model, the robustness function is formulated as the optimal objective value of an optimization problem with infinitely many constraint conditions. By using the semidefinite programming relaxation, we formulate the quasiconvex programming problem which provides the lower bounds of the robustness functions. A bisection method is proposed, where we solve a finite number of semidefinite programming problems. The lower bounds of robustness functions are computed for various trusses under several uncertain circumstances.
\end{abstract}

Keywords: robustness; data uncertainty; info-gap model; semidefinite program; semi-infinite program; quasiconvex program

ロバスト性, 不確定性, インフォ・ギャップモデル, 半正定值計画法, 半無限計画法, 準 凸計画法

\section{1 序}

構造物の設計において, 確定論的な構造最適化問題とその解法に ついては既に種々の提案がなされている。しかし，構造物および外 乱を特徴づけるパラメー夕は, 種々の理由により，一価の值に定ま らないことが多い.これらのパラメータが，ある数理的なモデルに 従って変動するとき, そのパラメー夕は不確定性を有するという. 近年, 構造物および外乱が持つ種々のパラメー夕の不確定性を考慮 し，パラメー夕変動に対する構造物の頑強さ (ロバスト性) を評価す る方法や，ロバスト性を考慮した構造物の設計法 (ロバスト設計法) が注目を集めている.これらの多くは，構造物の敏感性や信頼性に 基づいてロバスト性を評価する様々な指標を定義し，ロバスト性の 大きい設計を得ることを意図している ${ }^{1-9}$.

構造系が持つパラメータの不確定性のモデルには, 大別して確率 論的モデルと非確率論的モデルの 2 つがある. 確率論的不確定性 モデルは, 例えば, 構造物の性能制約が満たされない確率 (failure probability) を最小化する信頼性設計に用いられている。この確率を 直接求めることは計算時間の観点から困難であるため, モンテカル
口法 ${ }^{1}$ や応答曲面法 ${ }^{2}$, 感度解析法 ${ }^{3}$, reliability index 法 ${ }^{4}$ などが用 いられる. Doltsinis and Kang ${ }^{5}$ は, 多目的最適化手法に基づき, 要 求性能を表す関数の感度係数の期待値と標準偏差の双方を最小化す る構造最適化問題を定式化した.

非確率論的な不確定性のモデルとしては，凸モデル (convex model) 解析 ${ }^{10}$ がよく知られている. 一方, Ben-Tal and Nemirovski ${ }^{11}$ は, 種々 の錐線形計画問題 ${ }^{12}$ の係数が不確定性を含む場合のロバスト最適化 の概念と手法を提案した. Calafiore and El Ghaoui ${ }^{13}$ は半正定值計 画 (semidefinite program, SDP) 緩和 ${ }^{14}$ を用い, 線形方程式の係数が 不確定性を含む場合に，その解集合を含む棈円体を求める手法を提 案した。構造物に対する研究として, Pantelides and Ganzerli ${ }^{7}$ は凸 モデルに基づく不確定性を考慮したトラスの構造最適化問題を提案 した. また, Han and $\mathrm{Kwak}^{8}$ は, 構造物の要求性能を定める関数の

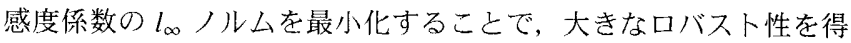
る手法を提案した。同様に, 曽我部 9 は多目的最適化手法に基づき, 骨組の崩壊荷重の感度係数と構造質量の双方を最小化する問題を定 式化した。

\footnotetext{
*1 京都大学大学院都市環境丁学専攻 助手・博士 (T学)

*2 京都大学大学院都市環境工学尃攻 教授・工博

Research Assoc., Dept. of Urban and Environmental Engineering, Kyoto University, Dr. Eng.

Prof., Dept. of Urban and Environmental Engineering, Kyoto University, Dr. Eng.
} 
Ben-Haim ${ }^{15}$ はインフォ・ギャップ決定理論 (info-gap decision theory) に基づき，ロバストネス関数 (robustness function) と呼ばれる関数を 新たに定義した。ロバストネス関数は，ロバスト性の定量的な指標 の1つと捉えることができる. インフォ・ギャップモデルでは，構 造系のパラメータが非確率論的な不確定性を持つことを仮定し，そ の不確定性のレベル, 即ちパラメータの変動の幅を 1 つのパラメー 夕 $\alpha$ を用いて表す，ロバストネス関数 $\bar{\alpha}$ は，構造系が必ず性能制 約を満たすような $\alpha$ の最大値として定義される ${ }^{16,17}$.

確率論的な不確定性モデルに基づく信頼性理論では，不確定なパ ラメータの確率分布や変動の大きさを推定する必要がある．契際に は，これらの統計量を正確に予測することは極めて困難な場合が多 い，これに対して，ロバストネス関数の利点は，不確定なパラメー 夕に関する統計量が一切必要ないことである15。しかし，ロバスト ネス関数は, 無限個の制約条件之有限個の変数を持つ数理計画問題 の最適値として定式化される ${ }^{17}$ 。このような問題は，半無限計画問 題 (semi-infinite programming problem) ${ }^{18}$ と呼ばれ，個々の問題が持 つ特殊な性質を利用しない限り，最適解を求めることは困難である. 従って，ロバストネ久関数を効率よく求める手法を開発することは, 工学上の重要な課題である.しかし，構造物の剛性が不確定性を持 つ場合にロバストネス関数を効㻭よく求める手法は，著者らの知る 限り提案されていない.

本稿の目的は，応力制約を有するトラスについて，外执び部 材剛性がインフォ・ギャップモデル15 に基づく不確定性を有する場 合のロバストネス関数を考え，その近似解を求める効㻭的な和法を 提案することにある．外力のみが不確定性を有する場合には，[1バ ストネス関数の正解を比較的谷易に得ることができる17。吉川 ${ }^{19}$ は, 外力の夕が不確定性を有する場命に，コンプライアンス制約を有す るトラスのロバストネス関数鼠大化問題を数值的に解いている。 こ れに対し，剛性行列が不確定性を持つ場合には，釣合式を満たす変 位の正確な上界や下界を求める問題は，NP 困難であることが知ら れている ${ }^{20}$ (NP 困難と計算複雑度については，例えば久保21を参 照). 従って，剛性行列が不確定性を持つ場合には，トラスが念力制

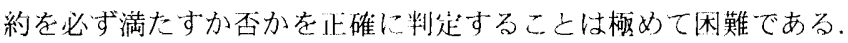
このような場合にロバストネス関数の正解を得ることは困難であり， その近似解を得る効率的な手法を開発することは重琶である。

本稿の第 2 節では，応力制約に関するトラスのロバストネ久関 数が，半無限計画問題 ${ }^{18}$ の最適値上して定義されることを示す。ま た, 第 3 節以降の数学的な準備として, SDP 問題 ${ }^{14}$ および淮凸計 画問題 22 について記述する。第 3 節では，簡単なトラスの例題を 用いてロバストネス関数の工学的な意味を説明する。第 4 節では， SDP 緩和 23 を用い，ロバストネ久関数の下界を求めるための(有限 次元の) 数理計画問題を定式化する. 第 5 節では，第 4 節の数理計 画問題に対し，二分法 ${ }^{24}$ に基つういて有限個の SDP 問題を解くこと で大域的最適解を得るアルゴリズムを提案する．第 6 節では，数值 例題を通じ，提案手法の有効性を示す。

\section{2 ロバストネス関数と半正定値計画法}

本稿では， $a_{1}, \ldots, a_{n}$ を要素とし，要素間に順序のない集合を $\left\{a_{1}, \ldots, a_{n}\right\}$, 順序のある集合を $\left(a_{1}, \ldots, a_{n}\right)$ で表す。ベクトル $\boldsymbol{p} \in \mathbf{R}^{n}$ は列ベクトルとし，その第 $i$ 成分を $p_{i}$ で表す。ベクトルの要素は 牘序のある集合なので, $\boldsymbol{p}=\left(p_{1}, \ldots, p_{n}\right)=\left(p_{i}\right)_{i=1}^{n}$ と書く. 特に, そ
の次元が明確であるときには $\boldsymbol{p}=\left(p_{i}\right)$ と書く. ベクトル $\boldsymbol{p}$ の Euclid ノルム $\left(\boldsymbol{p}^{\top} \boldsymbol{p}\right)^{1 / 2}$ を $\|\boldsymbol{p}\|_{2}$ で表す.さらに, ベクトル $\boldsymbol{p} \in \mathbf{R}^{n}$ が $p_{i} \geq 0$, $i=1, \ldots, n$, を満たすとき, $\boldsymbol{p} \geq \mathbf{0}$ と書く.

集合 $X \subseteq \mathbf{R}^{n}$ と $Y \subseteq \mathbf{R}^{m}$ の直積 $X \times Y$ を $X \times Y=\left\{\left(\boldsymbol{x}^{\top}, \boldsymbol{y}^{\top}\right)^{\top} \mid \boldsymbol{x} \in\right.$ $X, \boldsymbol{y} \in Y\}$ で定義する. 特に, $\mathbf{R}^{m} \times \mathbf{R}^{n}$ を $\mathbf{R}^{m+n}$ と書く. また, $n \times n$ 対称行列全体の集合を $\mathcal{S}^{n} \subset \mathbf{R}^{n \times n}$ で表す。

\section{1 応力制約に関するロバストネス関数}

本節では, 応力制約を持つトラスのロバストネス関数が，無限個 の制約条件を持つ数理計画問題の最適值として得られることを示す. 線形弾性を仮定し， 3 次元空間内のトラスを考える. $u \in \mathbf{R}^{n^{u}}$ を 節点変位, $f \in \mathbf{R}^{n^{\mathrm{d}}}$ を外力とおく.ただし,$n^{\mathrm{d}}$ は変位の自由度であ る. トラスの剛性行列を $\boldsymbol{K} \in \mathcal{S}^{n^{\mathrm{d}}}$ とおくと，釣合式は，

$$
K u=f
$$

で与えられる，部材数を $n^{\mathrm{m}}$ とおき，部材断面積から構成されるべ クトルを $\boldsymbol{a}=\left(a_{i}\right) \in \mathbf{R}^{n^{\mathrm{m}}}$ とおく.ここで, $\operatorname{rank}\left(\partial \boldsymbol{K} / \partial a_{i}\right)=1$ である ことを用いると，定べクトル $\boldsymbol{b}_{i}=\left(b_{i j}\right) \in \mathbf{R}^{n^{\mathrm{d}}}, i=1, \ldots, n^{\mathrm{m}}$ ，を用い て $K$ 沈次式のように表すことができる.

$$
\boldsymbol{K}(\boldsymbol{a})=\sum_{i=1}^{n^{\mathrm{m}}} a_{i} \boldsymbol{b}_{i} \boldsymbol{b}_{i}^{\top}
$$

ヤング係数を $E$ ，第 $i$ 部材の長さを $\ell_{i}$ とおくと，応力制約は

$$
\left|\sqrt{E / \ell_{i}} \boldsymbol{b}_{i}^{\top} \boldsymbol{u}\right| \leq \sigma_{i}^{\mathrm{c}}, \quad i=1, \ldots, n^{\mathrm{m}}
$$

と表される．ただし， $\mathbf{R} \ni \sigma_{i}^{\mathrm{c}}>0$ は第 $i$ 部材の許容応力である．以 トでは，(3)を特別な場合として含む次の制約条件を考慮する.

$$
u_{l}^{\mathrm{c}} \geq\left|\boldsymbol{d}_{l}^{\top} \boldsymbol{u}-r_{l}\right|, \quad l=1, \ldots, n^{\mathrm{c}} .
$$

ここで, $\mathbf{R}^{n^{c}} \ni \boldsymbol{u}^{\mathrm{c}}=\left(u_{l}^{\mathrm{c}}\right) \geq \mathbf{0}, \boldsymbol{d}_{l} \in \mathbf{R}^{n^{\mathrm{d}}}, r_{l} \in \mathbf{R}, l=1, \ldots, n^{\mathrm{c}}$, は定数で ある。さらに, $\mathbf{R}^{n^{i}}$ から $\mathbf{R}^{n^{d}} へ の$ 点-集合军像 $\mathcal{F} を$

$$
\mathcal{F}\left(\boldsymbol{u}^{\mathrm{c}}\right)=\left\{\boldsymbol{u} \in \mathbf{R}^{n^{\mathrm{d}}}\left|\boldsymbol{u}_{l}^{\mathrm{c}} \geq\right| \boldsymbol{d}_{l}^{\top} \boldsymbol{u}-r_{l} \mid, l=1, \ldots, n^{\mathrm{c}}\right\}
$$

で起義する．即ち， $\mathcal{F}\left(\boldsymbol{u}^{\mathfrak{c}}\right)$ は制約(4) を満たす $\boldsymbol{u}$ 全体の集合である. 部材剛性㧍よび外力の不確定性が， $n^{\zeta}$ 倜の不確定なパラメー夕 $\zeta_{1}, \ldots, \zeta_{n^{\circ}}$ を用いて表されるとする. また，パラメー夕 $\alpha$ を用いて $\zeta=\left(\zeta_{i}\right)$ の不確定性の大きさを表す．与えられた $\alpha>0$ に対し， $\zeta$ が取り得る值全体の集合, 即ち $\zeta$ の不確定性集合 (uncertainty set) をZ $(\alpha) \subset \mathbf{R}^{n^{r}}$ で表す (具体例は(20) 参照). インフォ・ギャップモデ ル 15 に基づき， Z $(\alpha)$ に対する以下の仮定を導入する.

仮定 2.1.
(i) $\mathcal{Z}(0)=\left\{\zeta \in \mathbf{R}^{n^{\xi}} \mid \zeta=\mathbf{0}\right\}$.
(ii) $0 \leq \alpha_{1}<\alpha_{2}$ ならば $\mathcal{Z}\left(\alpha_{1}\right) \subset \mathcal{Z}\left(\alpha_{2}\right)$.

$\boldsymbol{a}$ および $\boldsymbol{f}$ の公称值を $\widetilde{\boldsymbol{a}} \in \mathbf{R}^{n^{\mathrm{m}}}$ および $\widetilde{\boldsymbol{f}} \in \mathbf{R}^{n^{\mathrm{d}}}$ とおく. $\widetilde{\boldsymbol{a}}, \widetilde{\boldsymbol{f}}, \alpha \geq 0$ に対し， $\left(\boldsymbol{a}^{\top}, \boldsymbol{f}^{\top}\right)^{\top}$ の不確定性集合を $\mathcal{T}(\alpha, \tilde{a}, \tilde{f}) \subset \mathbf{R}^{n^{\mathrm{m}}} \times \mathbf{R}^{n^{\mathrm{d}}}$ で表す (具体例は (19) 参照)，簡単のため, $\mathcal{T}(\alpha, \widetilde{a}, \widetilde{f})$ を $\mathcal{T}(\alpha)$ または $\mathcal{T}$ と 書くことがある。

釣合式(1) の解 $\boldsymbol{u}$ 全体の集合を $\mathcal{U}(\alpha, \widetilde{\boldsymbol{a}}) \subseteq \mathbf{R}^{n^{d}}$ とおく． 即ち，

$$
\begin{aligned}
\mathcal{U}(\alpha, \widetilde{\boldsymbol{a}})=\left\{\boldsymbol{u} \in \mathbf{R}^{n^{\mathrm{d}}} \mid \boldsymbol{K}(\boldsymbol{a}) \boldsymbol{u}=\boldsymbol{f},\right. & \\
& \text { for some } \left.\left(\boldsymbol{a}^{\top}, \boldsymbol{f}^{\top}\right)^{\top} \in \mathcal{T}(\alpha, \widetilde{\boldsymbol{a}}, \widetilde{f})\right\} .
\end{aligned}
$$




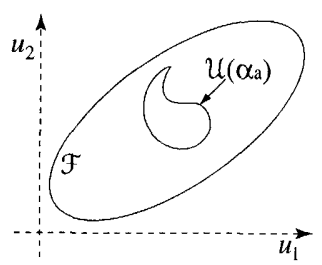

(a) $\alpha_{\mathrm{a}}<\widehat{\alpha}$

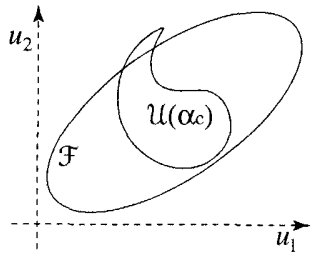

(c) $\alpha_{c}>\widehat{\alpha}$

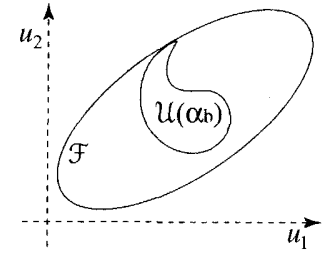

(b) $\alpha_{\mathrm{b}}=\widehat{\alpha}$

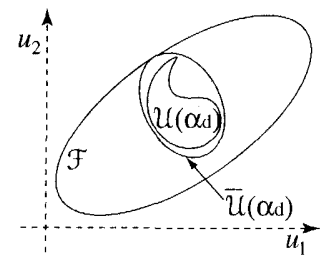

(d) $\overline{\mathcal{U}}\left(\alpha_{\mathrm{d}}\right)$ による緩和 $\left(\alpha_{\mathrm{d}} \leq \widehat{\alpha}\right)$
図 $1 \mathcal{F}\left(\boldsymbol{u}^{\mathrm{c}}\right), \mathcal{U}(\alpha, \widetilde{\boldsymbol{a}}), \overline{\mathcal{U}}(\alpha, \widetilde{\boldsymbol{a}})$ と $\widehat{\alpha}\left(\widetilde{\boldsymbol{a}}, \boldsymbol{u}^{\mathrm{c}}\right)$ の関係

制約条件(4)に関するロバストネス関数 $\widehat{\alpha}: \mathbf{R}^{n^{\mathrm{m}}+n^{\mathrm{c}}} \mapsto[0,+\infty]$ は, 次 式で定義される (Ben-Haim ${ }^{15}$, Ch. 3).

$$
\widehat{\alpha}\left(\widetilde{a}, \boldsymbol{u}^{\mathfrak{c}}\right)=\max \left\{\alpha \mid \boldsymbol{u} \in \mathcal{F}\left(\boldsymbol{u}^{\mathrm{c}}\right), \forall \boldsymbol{u} \in \mathcal{U}(\alpha, \widetilde{a})\right\} .
$$

問題 (7) が実行不能ならば, $\widehat{\alpha}\left(\boldsymbol{a}, \boldsymbol{u}^{\mathfrak{c}}\right)=0$ と定義する. $\tilde{\boldsymbol{a}}^{1} \in \mathbf{R}^{n^{\mathrm{m}}}$ お よび $\widetilde{\boldsymbol{a}}^{2} \in \mathbf{R}^{n^{\mathrm{m}}}$ が条件 $\widehat{\alpha}\left(\boldsymbol{a}^{1}, \boldsymbol{u}^{\mathrm{c}}\right)>\widehat{\alpha}\left(\boldsymbol{a}^{2}, \boldsymbol{u}^{\mathrm{c}}\right)$ を満たすとき, $\widetilde{\boldsymbol{a}}^{1}$ は $\overrightarrow{\boldsymbol{a}}^{2}$ よりもロバスト性が大きいという． $\boldsymbol{\zeta}^{1} \in \mathcal{Z}\left(\widehat{\alpha}\left(\boldsymbol{a}^{1}, u^{\mathrm{c}}\right)\right)$ に対して等式 $u_{l}^{\mathrm{c}}=\left|\boldsymbol{d}_{l}^{\top} \boldsymbol{u}-r_{l}\right|$ が成立する $l \in\left\{1, \ldots, n^{\mathrm{c}}\right\}$ が存在するとき， $\boldsymbol{\zeta}^{1}$ は最悪 事例 (worst case) であるという.

ロバストネス関数 $\widehat{\alpha}\left(\boldsymbol{a}, \boldsymbol{u}^{\mathfrak{c}}\right)$ と，種々の $\alpha$ に対する集合 $\mathcal{F}\left(\boldsymbol{u}^{\mathfrak{c}}\right)$ お よび $\mathcal{U}(\alpha, \widetilde{a})$ との関係を図 1 (a)-(c) に示す. $\alpha_{\mathrm{a}}<\widehat{\alpha}\left(\widetilde{a}, \boldsymbol{u}^{\mathrm{c}}\right)$ および $\alpha_{b}=\widehat{\alpha}\left(\vec{a}, \boldsymbol{u}^{\mathrm{c}}\right)$ に対応する図 1 (a) および (b) では, 全ての場合に制 約条件 $u \in \mathcal{F}\left(\boldsymbol{u}^{\mathfrak{c}}\right)$ が満たされている，一方，図 1 (c) では, 釣合式 の解 $\boldsymbol{u} \in \mathcal{U}\left(\alpha_{\mathrm{c}}, \widetilde{a}\right)$ が $\boldsymbol{u} \in \mathcal{F}\left(\boldsymbol{u}^{\mathrm{c}}\right)$ を満たさない場合が存在するので, $\alpha_{\mathrm{c}}>\widehat{\alpha}\left(\boldsymbol{a}, \boldsymbol{u}^{\mathfrak{c}}\right)$ である. 問題(7) は, $\mathcal{U}(\alpha, \widetilde{\boldsymbol{a}})$ が $\mathcal{F}\left(\boldsymbol{u}^{\mathrm{c}}\right)$ に含まれる場合 の中で最大の $\alpha$ を求める問題である.

このように，ロバストネス関数 $\widehat{\alpha}$ は問題 (7) の最大值として得ら れる.しかし, 不確定パラメータ $ら$ の組合せは無限に存在するため, 問題 (7) は無限個の制約条件を含む.このような問題は半無限計画 問題 ${ }^{18}$ と呼ばれ，実際に解を求めることは極めて困難である. そこ で，第 4 節では， $\bar{\alpha}$ の界を効率よく求める手法を展開する.

\section{2 半正定值計画問題}

$\boldsymbol{P} \in \mathcal{S}^{n}$ に対して, 行列 $\boldsymbol{P}$ が半正定値であるとき, 即ち $\boldsymbol{P}$ の全て の固有値が非負であるとき, $\boldsymbol{P} \geq \boldsymbol{O}$ と書く. また， $\boldsymbol{Q} \in \mathcal{S}^{n}, \boldsymbol{W} \in \mathcal{S}^{n}$ に対して行列 $(Q-W)$ が半正定值であるとき, $Q \geq W$ と書く. 行列 $\boldsymbol{P} \in \mathcal{S}^{n}$ と $\boldsymbol{Q} \in \mathcal{S}^{n}$ の内積を $\boldsymbol{P} \bullet \boldsymbol{Q}=\operatorname{tr}\left(\boldsymbol{P}^{\top} \boldsymbol{Q}\right)=\sum_{i=1}^{n} \sum_{j=1}^{n} P_{i j} Q_{i j}$ で定 義する.

次の数理計画問題を, 半正定值計画問題 (semidefinite programming problem, SDP 問題) の等式標準形の主問題と呼ぶ 25 .

$$
\left.\begin{array}{ll}
\text { Minimize } & \boldsymbol{C} \bullet \boldsymbol{X} \\
\text { subject to } & \boldsymbol{A}_{i} \bullet \boldsymbol{X}=b_{i}, \quad i=1, \ldots, m, \\
& \mathcal{S}^{n} \ni \boldsymbol{X} \geq \boldsymbol{O} .
\end{array}\right\}
$$

ここで, $\boldsymbol{X}$ は変数行列, $\boldsymbol{A}_{i} \in \mathcal{S}^{n}, i=1, \ldots, m, \boldsymbol{b}=\left(b_{i}\right) \in \mathbf{R}^{m}, \boldsymbol{C} \in \mathcal{S}^{n}$ は定行列および定べクトルである. 問題 (8) の双対問題は, $y \in \mathbf{R}^{m}$
を変数とする次の問題で与えられる.

$$
\left.\begin{array}{ll}
\text { Maximize } & \boldsymbol{b}^{\top} \boldsymbol{y} \\
\text { subject to } & \boldsymbol{C}-\sum_{i=1}^{m} \boldsymbol{A}_{i} y_{i} \geq \boldsymbol{O} .
\end{array}\right\}
$$

SDP 問題 (8) および(9)の制約条件は, 線形行列不等式 (linear matrix inequality) 亡呼ばれ，双方の問題の実行可能領域は凸集合であるこ とが知られている25.

半正定值計画法は線形計画法や凸 2 次計画法などを含んでおり 従来よりも広い範囲の凸計画問題を扳うことができる，さらに，主 双対内点法と呼ばれる多項式性を持つ解法が提案され25，それに基 づくソフトウェアもいくつか実装さ扎ている26. 主双対内点法を用 いると, SDP問題 (8) および (9) の大域的最適解を得るために必要 な四則演算の回数が $n$ および $m$ の多項式で押さえられる。このた めSDP は，システム制御への応用，組合せ最適化問題に対する緩 和問題など様々な分野で注目されている12,14。また，組合せ最適化 および非凸型 2 次計画問題に対ずる SDP 緩和は, 従来の線形計画 緩和に比べて理論的に優れているこ上が知られている14,23. 著者ら は, SDP を用い, 1 次固有振動数 ${ }^{27}$ 㧍よび線形座屈荷重係数 28 の 制約の下でのトラスのトポロジー最適化問題に対し，最適解で最小 固有值が多数重複する場合にも効率よく解を得る手法を提案した。 Ben-Tal and Nemirovski ${ }^{6}$ は，不確定性を含んだ外力に対するトラス のコンプライアンス最小化問題を SDP 問題として定式化している.

\section{3 準凸計画問題}

関数 $f: \mathbf{R}^{n} \mapsto \mathbf{R}$ と $\beta \in \mathbf{R}$ に対して定義される集合

$$
\mathcal{L}_{f}(\beta)=\left\{x \in \mathbf{R}^{n} \mid f(x) \leq \beta\right\}
$$

を $f$ のレベル集合 (level set) と㭔ぶ。任意の $\beta \in \mathbf{R}$ に対してレベル集 合 $\mathcal{L}_{f}(\beta)$ が凸集合である関数 $f$ を，準凸関数 (quasiconvex function) 乙いう29.

関数 $f_{i}: \mathbf{R}^{n} \mapsto \mathbf{R}, i=0,1, \ldots, m$, および $\boldsymbol{A} \in \mathbf{R}^{m \times n}, \boldsymbol{b} \in \mathbf{R}^{m}$ を用い て定義される数理計画問題

$$
\left.\begin{array}{ll}
\text { Minimize } & f_{0}(\boldsymbol{x}) \\
\text { subject to } & f_{i}(\boldsymbol{x}) \leq 0, \quad i=1, \ldots, m, \\
& \boldsymbol{A} \boldsymbol{x}=\boldsymbol{b},
\end{array}\right\}
$$

を考える. $f_{0}$ が準凸関数， $f_{3}, \ldots, f_{m}$ が凹関数であるとき，問題 $(10)$ を準凸計画問題 (quasiconvex programming probiem) ${ }^{22}$ 上呼ぶ。

\section{4 線形行列不等式に関する補題}

次節以降のために，次の 2 つの補題を導入しておく。

補題 2.2. $Q \in \mathcal{S}^{n}, p \in \mathbf{R}^{n}, v \in \mathbf{R}$ に対し，条件

$$
\left(\begin{array}{l}
\xi \\
1
\end{array}\right)^{\top}\left(\begin{array}{cc}
Q & p \\
p^{\top} & v
\end{array}\right)\left(\begin{array}{l}
\xi \\
1
\end{array}\right) \geq 0, \quad \forall \xi \in \mathbf{R}^{n}
$$

が成立するための必要十分条件は，

$$
\left(\begin{array}{ll}
Q & p \\
p^{\top} & v
\end{array}\right) \geq O
$$

が成り立つことである。

証明. Calafiore and El Ghaoui ${ }^{13}$, Lemma A.3 0)証明を参照。 


\section{(a)}

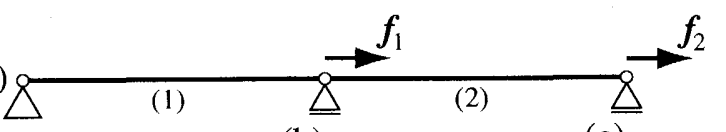

(b)

(c)

図 22 自由度静定トラス

補題 2.3 (S-Lemma). $Q_{i} \in \mathcal{S}^{n}, p_{i} \in \mathbf{R}^{n}, d_{i} \in \mathbf{R}, i=0, \ldots, m$, に対し, 関数 $f_{i}: \mathbf{R}^{n} \mapsto \mathbf{R}$ を

$$
f_{i}(\xi)=\boldsymbol{\xi}^{\top} \boldsymbol{Q}_{i} \boldsymbol{\xi}+2 \boldsymbol{p}_{i}^{\top} \boldsymbol{\xi}+d_{i}, \quad i=0, \ldots, m
$$

で定義する. 命題

$$
f_{1}(\xi) \geq 0, \ldots, f_{m}(\xi) \geq 0 \quad \Longrightarrow \quad f_{0}(\xi) \geq 0
$$

が真であるための十分条件は,

$$
f_{0}(\boldsymbol{\xi})-\sum_{i=1}^{m} \tau_{i} f_{i}(\boldsymbol{\xi}) \geq 0, \quad \forall \boldsymbol{\xi} \in \mathbf{R}^{n}
$$

を満たす $\tau_{1}, \ldots, \tau_{m} \geq 0$ が存在することである.

証明. 非凸型 2 次計画問題の半正定值計画緩和 (SDP 緩和) に対す る双対定理より得られる. Ben-Tal and Nemirovski ${ }^{12}$, Ch.4 および Wolkowicz et al. ${ }^{14}, \S 6.3 .1$ の証明を参照.

非凸型 2 次計画問題のSDP 緩和に関しては，例えば Fujie and Kojima ${ }^{23}$ を参照.

\section{3 ロバストネス関数の例}

本節では，ロバストネス関数の概念を説明するために，四 2 に示 す線形弾性トラスの[]バストネス関数を解析的に求める. 節点 (a) はピン支持されており, 節点 (b) および (c) には, それぞれ, 外力 $f_{1}$ および $f_{2}$ が作用する. 節点 (b) および (c) の変位を $u_{1}$ および $u_{2}$ とおく. また, 部材 (1) と (2)の部材長は等しい. 外力のみが不確定 性を持つ場合のこのトラスのロバストネス関数に関しては, Kanno and Takewaki ${ }^{17}, \S 3$ を参照. 部材断面積を $a_{1}, a_{2}$ と㧍くと, 部材応 力 $\sigma_{i}$ は

$$
\sigma_{1}=\frac{f_{1}+f_{2}}{a_{1}}, \quad \sigma_{2}=\frac{f_{2}}{a_{2}}
$$

で与えられる．定数 $\sigma^{\mathfrak{c}}>0$ を与え，念力制約

$$
\left|\sigma_{i}\right| \leq \sigma^{\mathrm{c}}, \quad i=1,2
$$

を考慮する.

インフォ・ギャップ不確定性モデル15 に基づき， $\left(a_{1}, a_{2}\right)^{\top}$ および $\left(f_{1}, f_{2}\right)^{\top}$ がパラメータとを用いて

$$
\begin{aligned}
& a_{1}=\tilde{a}_{1}+\zeta a^{1}, \quad a_{2}=\widetilde{a}_{2}+\zeta a^{2}, \\
& f_{1}=f_{2}=\widetilde{f}+\zeta f^{1}, \quad \alpha \geq|\zeta|, \quad \alpha \geq 0
\end{aligned}
$$

で表されることを仮定する。ここで， $\widetilde{f} は f_{1}$ 执よび $f_{2}$ の公称值, $\left(\widetilde{a}_{1}, \tilde{a}_{2}\right)^{\top}$ は $\left(a_{1}, a_{2}\right)^{\top}$ の公称值である. また, $a^{1}, a^{2}, f^{1}$ は, $\boldsymbol{a}$ と $\boldsymbol{f}$ の 不確定性の相対的な大きさを表す定数である. 明らかに, (15) で定 義される不確定性集合は仮定 2.1 を満たす，以下では，簡単のため

$$
f^{1} \widetilde{a}_{1}>\widetilde{f} a^{1}, \quad f^{1} \widetilde{a}_{2}>\widetilde{f} a^{2}, \quad \widetilde{f}>0
$$

および $a^{1}=a^{2}=1.0 \mathrm{~cm}^{2}, f^{1}=9.8 \mathrm{kN}$ とおく. ロバストネス関数 $\widehat{\alpha}\left(\boldsymbol{a}, \sigma^{\mathfrak{c}}\right)$ の定義は, (15) を満たす任意の $\left(a_{1}, a_{2}\right)^{\top},\left(f_{1}, f_{2}\right)^{\top}$ に対して 条件(14) が満たされる $\alpha$ の最大值である. (13), (16)より,

$$
\frac{\partial \sigma_{1}}{\partial \zeta}=\frac{2\left(f^{1} \widetilde{a}_{1}-\widetilde{f} a^{1}\right)}{\left(\widetilde{a}_{1}+\zeta a^{1}\right)^{2}}>0, \quad \frac{\partial \sigma_{2}}{\partial \zeta}=\frac{\left(f^{1} \widetilde{a}_{2}-\widetilde{f}^{2}\right)}{\left(\widetilde{a}_{1}+\zeta a^{1}\right)^{2}}>0
$$

が得られる. 従って, 応力の絶対値の最大值は,

$$
\begin{aligned}
& \max _{\zeta \in \mathbf{R}}\left\{\left|\sigma_{1}\right||\alpha \geq| \zeta \mid\right\}=\frac{2\left(\widetilde{f}+\alpha f^{1}\right)}{\widetilde{a}_{1}+\alpha a^{1}}, \\
& \max _{\zeta \in \mathbf{R}}\left\{\left|\sigma_{2}\right||\alpha \geq| \zeta \mid\right\}=\frac{\widetilde{f}+\alpha f^{1}}{\widetilde{a}_{2}+\alpha a^{2}}
\end{aligned}
$$

である.

$\widetilde{f}=9.8 \mathrm{kN}, \sigma^{\mathfrak{c}}=19.6 \mathrm{MPa}$ とおく. 2 つの部材断面積ベクトル $\boldsymbol{a}_{1}=(15,15)^{\top} \mathrm{cm}^{2}$ および $\boldsymbol{a}_{2}=(20,10)^{\top} \mathrm{cm}^{2}$ を考える. ただし， $\boldsymbol{a}_{1}$ と $\boldsymbol{a}_{2}$ の構造質量は等しい. 最初に $\tilde{\boldsymbol{a}}=\boldsymbol{a}_{1}$ とおく. (17) より, $\max \left\{\left|\sigma_{1}\right||\alpha \geq| \zeta \mid\right\}$ は $\alpha=5 / 9$ において $\sigma^{\mathrm{c}}$ に到達する. 一方, (18)よ り, $\max \left\{\left|\sigma_{2}\right||\alpha \geq| \zeta \mid\right\}$ は $\alpha=2.5$ において $\sigma^{c}$ に到達する. 従って, ロバストネス関数は $\widehat{\alpha}\left(a_{1}, \sigma^{c}\right)=5 / 9$ と得られる.これは, 断面積之 外力が(15) および $\alpha=5 / 9$ を満たすならば，制約条件(14)が必ず満 たされることを意味する.

次に, $\tilde{\boldsymbol{a}}=\boldsymbol{a}_{2}$ とおくと, (17)より, $\max \left\{\left|\sigma_{1}\right||\alpha \geq| \xi \mid\right\}$ は $\alpha=10 / 9 \simeq$ 1.11 のとき $\sigma^{\mathrm{c}}$ に到達する. 一方, (18)より, $\max \left\{\left|\sigma_{2}\right||\alpha \geq| \xi \mid\right\}$ は $\alpha=1.25$ において $\sigma^{\mathfrak{c}}$ に到達する. 以上より, $\widehat{\alpha}\left(\boldsymbol{a}_{2}, \boldsymbol{\sigma}^{\mathfrak{c}}\right)=10 / 9$ が得 られる. 従って, $a_{2}$ のロバストネス関数は $a_{1}$ のそれよりも大きい, 即ち, $a_{2}$ は $a_{1}$ よりもロバスト性が大きいことが分かる.

一般のトラスに対しては，本節のようにロバストネス関数を解析 的に求めることは極めて困難である. 次節以降では，ロバストネス 関数の近似值を効率よく求める手法を提案する.

\section{4 半正定值計画緩和に基づくロバストネス関数の近似解}

ロバストネス関数 $\widehat{\alpha}\left(\boldsymbol{a}, \boldsymbol{u}^{\mathfrak{c}}\right)$ を直接求めることは, 半無限計画問 題 (7) の大域的最適解を求めることと等価であるから，実際には極 めて困難である. 従って, ロバストネス関数の近似解を求める効率 的な手法を提案することは意義がある.

自然数 $n^{\mathrm{a}}$ に対し、ベクトル $\boldsymbol{e}^{n} \in \mathbf{R}^{n^{\mathrm{m}}}$ を

$$
e_{j}^{p}=\left\{\begin{array}{ll}
1, & \text { if } j=p, \\
0, & \text { otherwise, }
\end{array} \quad p=1, \ldots, n^{\mathrm{a}}\right.
$$

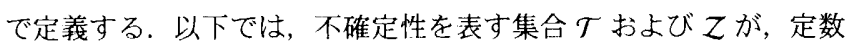
$a^{1}, \ldots, a^{n^{n}} \in \mathbf{R}, f^{1}, \ldots, f^{n^{1}} \in \mathbf{R}^{n^{d}}$ を用いて

$$
\begin{gathered}
\mathcal{T}(\alpha, \widetilde{\boldsymbol{a}}, \tilde{\boldsymbol{f}})=\left\{\left(\sum_{p=1}^{n^{\mathrm{a}}} \zeta_{p} a^{p}\left(\boldsymbol{e}^{p}\right)^{\top}, \sum_{p=1}^{n^{\mathrm{T}}} \zeta_{n^{\mathrm{a}}+p}\left(\boldsymbol{f}^{p}\right)^{\top}\right)^{\top}\right. \\
\left.+\left(\widetilde{\boldsymbol{a}}^{\top}, \widetilde{\boldsymbol{f}}^{\top}\right)^{\top} \mid \zeta \in \mathcal{Z}(\alpha)\right\}, \\
\mathcal{Z}(\alpha)=\left\{\zeta \in \mathbf{R}^{n^{\mathrm{a}}+n^{\mathrm{f}}} \mid \alpha \geq\|\boldsymbol{\zeta}\|_{2}\right\}
\end{gathered}
$$

と表せることを仮定する（20) で定義される乙は仮定 2.1 を満た すので, (19), (20) はインフォ・ギャップ不確定性モデル15 に従う.

いま， $\zeta^{1} \in \mathbf{R}^{n^{a}+n^{\mathrm{f}}}$ を選び，制約条件(4) が満たされるか否かを判 定する． $\zeta^{1}$ を固定すると，変位 $\boldsymbol{u}$ は $\zeta^{1}$ に対する通常の釣合式を 解くことで直ちに得られるので，この判定は容易に実行できる．こ のとき, 条件(4) のいずれかが満たされないならば, (7), (20)より $\widehat{\alpha}<\left\|\zeta^{1}\right\|_{2}$ を得る. 即ち, $\left\|\zeta^{1}\right\|_{2}$ がロバストネス関数 $\widehat{\alpha}$ の界である ことは, 容易に示すことができる. 一方， $\underline{\alpha}>0$ が $\alpha$ の下界である こと，即ち $\widehat{\alpha} \geq \underline{\alpha}$ を示すことを考える.このためには， $\zeta \in \mathcal{Z}(\underline{\alpha})$ を 満たす全てのらに対して条件(4)が満たされることを示さなければ ならない. 従って, ロバストネス関数の下界を求めることは, 上界 を求めることよりも困難である. 
ロバストネス関数の下界 $\alpha$ が得られたとする．このとき， $\zeta \in Z(\underline{\alpha})$ を満たす任意の らに対して, 制約条件(4) が満たされることが保証 される. 従って, ロバストネス関数の精度の良い下界を求めること は，工学的に大きな意味がある，以下では，SDP 緩和に基づき，口 バストネス関数の下界を効率よく求める手法を提案する.

写像 $H_{l}: \mathbf{R} \mapsto \mathcal{S}^{n^{\mathrm{d}+1}}, l=1, \ldots, n^{\mathrm{c}}$, を

$$
\boldsymbol{H}_{l}\left(u_{l}^{\mathrm{c}}\right)=\left(\begin{array}{cc}
-\boldsymbol{d}_{l} \boldsymbol{d}_{l}^{\top} & r_{l} \boldsymbol{d}_{l} \\
r_{l} \boldsymbol{d}_{l}^{\top} & \left(u_{l}^{\mathrm{c}}\right)^{2}-r_{l}^{2}
\end{array}\right)
$$

で定義する. (4) 式の条件 $u_{l}^{\mathrm{c}} \geq\left|\boldsymbol{d}_{l}^{\top} \boldsymbol{u}-\boldsymbol{r}_{l}\right|$ は, 条件 $\left(u_{l}^{\mathrm{c}}\right)^{2}-\left(\boldsymbol{d}_{l}^{\top} \boldsymbol{u}-r_{l}\right)^{2} \geq 0$ と等価であるから，(5) で定義されるF は

$$
\boldsymbol{u} \in \mathcal{F}\left(\boldsymbol{u}^{\mathrm{c}}\right) \Longleftrightarrow\left(\begin{array}{l}
\boldsymbol{u} \\
1
\end{array}\right)^{\top} \boldsymbol{H}_{l}\left(u_{l}^{\mathrm{c}}\right)\left(\begin{array}{l}
\boldsymbol{u} \\
1
\end{array}\right) \geq 0, \quad l=1, \ldots, n^{\mathrm{c}}
$$

と書き直すことができる.

いま, 問題 (7) が実行不能であれば，定義より $\widehat{\alpha}\left(\boldsymbol{a}, \boldsymbol{u}^{\mathrm{c}}\right)=0$ であ る.これ以降は, 問題 (7) が実行可能であることを仮定する. 次の 命題は，ロバストネス関数の SDP 緩和に基づく下界を与える.

命題 4.1. 集合 $\mathcal{T}$ および Zが(19), (20) で与えられることを仮定す る. 行列 $\boldsymbol{\Omega}_{j} \in \mathcal{S}^{n^{\mathrm{d}}+1}$ を

$$
\begin{aligned}
& \boldsymbol{\Omega}_{j}\left(\alpha^{2}, \widetilde{\boldsymbol{a}}\right)=\left(\begin{array}{ll}
\boldsymbol{\Omega}_{j 11} & \omega_{j 12} \\
\boldsymbol{\omega}_{j 12}^{\top} & \omega_{j 22}
\end{array}\right), \\
& \boldsymbol{\Omega}_{j 11}=\left(\sum_{i=1}^{n^{\mathrm{m}}} \widetilde{a}_{i} b_{i j} \boldsymbol{b}_{i}\right)\left(\sum_{i=1}^{n^{\mathrm{m}}} \widetilde{a}_{i} b_{i j} \boldsymbol{b}_{i}^{\top}\right)-\alpha^{2} \sum_{p=1}^{n^{\mathrm{a}}}\left(a^{p}\right)^{2} b_{p j}^{2} \boldsymbol{b}_{p} \boldsymbol{b}_{p}^{\top}, \\
& \boldsymbol{\omega}_{j 12}=-\widetilde{f}_{j} \sum_{i=1}^{n^{\mathrm{m}}} \widetilde{a}_{i} b_{i j} \boldsymbol{b}_{i}, \\
& \omega_{j 22}=\widetilde{f}_{j}^{2}-\alpha^{2}\left\|\left(f_{j}^{p}\right)_{p=1}^{n^{\mathrm{f}}}\right\|_{2}^{2}
\end{aligned}
$$

で導入し， $\tau_{l}=\left(\tau_{l 1}, \ldots, \tau_{l n^{\mathrm{d}}}\right)^{\top}, \boldsymbol{\tau}=\left(\boldsymbol{\tau}_{1}^{\top}, \ldots, \boldsymbol{\tau}_{n^{\mathrm{c}}}^{\top}\right)^{\top}$ とおく. $\left(t, \tau^{\top}\right)^{\top} \in$ $\mathbf{R} \times \mathbf{R}^{n^{\mathrm{c}} n^{\mathrm{d}}}$ を変数とする次の数理計画問題を考える.

$$
\begin{aligned}
t^{*}:=\max \left\{t \mid \sum_{j=1}^{n^{\mathrm{d}}} \tau_{l j} \boldsymbol{\Omega}_{j}(t, \widetilde{\boldsymbol{a}})+\boldsymbol{H}_{l}\left(u_{l}^{\mathrm{c}}\right) \geq \boldsymbol{O},\right. \\
\left.\tau_{l 1}, \ldots \tau_{l n^{\mathrm{d}}} \geq 0, \quad l=1, \ldots, n^{\mathrm{c}}\right\} .
\end{aligned}
$$

このとき，ロバストネス関数 $\widehat{\alpha}\left(\widetilde{a}, u^{\mathfrak{c}}\right)$ は $\widehat{\alpha}\left(\widetilde{a}, u^{\mathfrak{c}}\right)^{2} \geq t^{*}$ を満たす。

証明. $\mathbf{R} \times \mathbf{R}^{n^{\mathrm{m}}}$ から $\mathbf{R}^{n^{\mathrm{d}}}$ への点-集合写像 $\overline{\mathcal{U}}$

$$
\overline{\mathcal{U}}(\alpha, \widetilde{\boldsymbol{a}})=\left\{\boldsymbol{u} \in \mathbf{R}^{n^{\mathrm{d}}} \mid-\left(\boldsymbol{u}^{\top}, 1\right) \boldsymbol{\Omega}_{j}\left(\alpha^{2}, \widetilde{\boldsymbol{a}}\right)\left(\boldsymbol{u}^{\top}, 1\right)^{\top} \geq 0, j=1, \ldots, n^{\mathrm{d}}\right\}
$$

で定義する.Uの定義(6) および(19),(20)より，

$$
\boldsymbol{u} \in \mathcal{U}(\alpha, \widetilde{\boldsymbol{a}}) \quad \Longrightarrow \quad \boldsymbol{u} \in \overline{\mathcal{U}}(\alpha, \overline{\boldsymbol{a}})
$$

が成り立つ. 補題 2.2 および $\mathcal{S}$-Lemma（補題 2.3) より，命題

$$
u \in \overline{\mathcal{U}}(\alpha, \widetilde{a}) \quad \Longrightarrow \quad u \in \mathcal{F}\left(\boldsymbol{u}^{\mathrm{c}}\right)
$$

が真であるための十分条件は,

$$
\boldsymbol{H}_{l}\left(u_{l}^{\mathrm{c}}\right) \geq-\sum_{j=1}^{n^{\mathrm{d}}} \tau_{l j} \boldsymbol{\Omega}_{j}\left(\alpha^{2}, \widetilde{\boldsymbol{a}}\right), \quad l=1, \ldots, n^{\mathrm{c}}
$$

を満たす $\tau_{l 1}, \ldots, \tau_{l n^{\mathrm{d}}} \geq 0$ が存在することである. (23), (24)より, 問 題 (22) の実行可能領域は問題 (7) の実行可能領域を含む. 従って題 意が成立し, 問題 (22) の解は問題 (7) の下界を与える.
$\mathcal{U}(\alpha, \widetilde{\boldsymbol{a}})$ と $\overline{\mathcal{U}}(\alpha, \widetilde{\boldsymbol{a}})$ の関係を, 図 1 (d) に模式的に示す. $\mathcal{U}(\alpha, \widetilde{\boldsymbol{a}})$ の代 わりに, $\overline{\mathcal{U}}(\alpha, \widetilde{\boldsymbol{a}})$ が $\mathcal{F}\left(\boldsymbol{u}^{\mathrm{c}}\right)$ に含まれる場合の中で最大の $\alpha$ を求める 問題を考える. 問題 (22) は，この問題のSDP 緩和に基づく近似解 を与える. 特に, 命題 4.1 は, (22) で定義される $\left(t^{*}\right)^{1 / 2}$ が 即ち保守的な近似解であることを表している. 従って, $\zeta \in Z\left(\left(t^{*}\right)^{1 / 2}\right)$ を満たす任意のらに対して制約条件(4) が満たされることが保証さ れる。

注意 4.2. 命題 4.1 において, 外力のみが不確定性を持つ場合, 即ち $a^{p}=0, p=1, \ldots, n^{\mathrm{a}}$,である場合を考える．このとき，

$$
g_{l}=\frac{\boldsymbol{d}_{l}^{\top} \boldsymbol{K}^{-1} \tilde{\boldsymbol{f}}+u_{l}^{\mathrm{c}}}{\left\|\left(\boldsymbol{d}_{l}^{\top} \boldsymbol{K}^{-1} \boldsymbol{f}^{p}\right)_{p=1}^{n^{\mathrm{T}}}\right\|_{2}}, \quad h_{l}=\frac{-\boldsymbol{d}_{l}^{\top} \boldsymbol{K}^{-1} \tilde{\boldsymbol{f}}+u_{l}^{\mathrm{c}}}{\left\|\left(\boldsymbol{d}_{l}^{\top} \boldsymbol{K}^{-1} \boldsymbol{f}^{p}\right)_{p=1}^{n^{1}}\right\|_{2}}
$$

とおくと，ロバストネス関数 $\widehat{\alpha}$ は次式で計算できる。

$$
\widehat{\alpha}\left(\boldsymbol{a}, \boldsymbol{u}^{\mathfrak{c}}\right)=\min _{l=1, \ldots, n^{\mathfrak{c}}}\left\{g_{l}, h_{l}\right\} .
$$

証明は Kanno and Takewaki ${ }^{17}$, Proposition 5.1 を参照.

5 半正定值計画法および二分法に基づくアルゴリズム

次の命題は, 問題 (22) の特徵を述べている.

命題 5.1. 問題 (22) は準凸計画問題である.

証明. 関数 $\phi: \mathbf{R}^{n^{c} n^{d}} \mapsto \mathbf{R}$ を，

$$
\begin{aligned}
& -t \geq \phi(\boldsymbol{\tau}) \quad \Longleftrightarrow \\
& \sum_{j=1}^{n^{d}} \tau_{l j} \boldsymbol{\Omega}_{j}(t, \widetilde{\boldsymbol{a}})+\boldsymbol{H}_{l}\left(u_{l}^{\mathrm{c}}\right) \geq \boldsymbol{O}, \quad l=1, \ldots, n^{\mathrm{c}}
\end{aligned}
$$

を満たすように定義すると, 問題 (22) は

$$
-t^{*}=\min \left\{\phi(\tau) \mid \tau_{l 1}, \ldots, \tau_{l n^{u}} \geq 0, \quad l=1, \ldots, n^{\mathrm{c}}\right\}
$$

と書き直せる. $\beta \in \mathbf{R}$ に対して集合 $\mathcal{L}_{\phi}(\beta) \subset \mathbf{R}^{n^{c} n^{d}}$ を

$$
\begin{aligned}
& \mathcal{L}_{\phi}(\beta)=\left\{\boldsymbol{\tau} \in \mathbf{R}^{n^{\mathrm{c}} n^{\mathrm{d}}} \mid\right. \\
& \left.\sum_{j=1}^{n^{\mathrm{d}}} \tau_{l j} \boldsymbol{\Omega}_{j}(-\beta, \overline{\boldsymbol{a}})+\boldsymbol{H}_{l}\left(u_{l}^{\mathrm{c}}\right) \geq \boldsymbol{O}, \quad l=1, \ldots, n^{\mathrm{c}}\right\}
\end{aligned}
$$

で定義すると， $\phi$ の作り方より， $\mathcal{L}_{\phi}(\beta)$ は $\phi$ のレベル集合である. 任 意の $\beta \in \mathbf{R}$ に対して， $\mathcal{L}_{\phi}(\beta)$ は線形行列不等式系を満たす $\tau \in \mathbf{R}^{n^{\mathrm{c}} n^{\mathrm{d}}}$ の集合であるから，凸集合である25. 従って，問題 $(25)$ の目的関数 $\phi$ は準凸関数である．このことから，問題 (25) 㹥準凸計画問題 (10) に帰着できる。

命題 5.1 は, 二分法 (bisection method) ${ }^{24}$ を用いることで, 問題 (22) の大域的最適解が得られることを表している。 $\left(t, \tilde{a}^{\top}\right)^{\top}$ を固定し， $\left(s, \boldsymbol{\tau}^{\top}\right)^{\top} \in \mathbf{R} \times \mathbf{R}^{n^{c} n^{\mathrm{d}}}$ を変数とする次の数理計画問題を考える.

$$
\begin{gathered}
s^{*}:=\min \left\{s \mid \sum_{j=1}^{n^{\mathrm{d}}} \tau_{l j} \boldsymbol{\Omega}_{j}(t, \widetilde{\boldsymbol{a}})+\boldsymbol{H}_{l}\left(u_{l}^{\mathrm{c}}\right)+\left(\begin{array}{cc}
\boldsymbol{O} & \mathbf{0} \\
\boldsymbol{0}^{\top} & s
\end{array}\right) \geq \boldsymbol{O},\right. \\
\left.\boldsymbol{\tau}_{l} \geq \mathbf{0}, \quad l=1, \ldots, n^{\mathrm{c}}\right\} .
\end{gathered}
$$

問題 (26) は，SDP 問題 (9) に州着させることができる. 問題 (26) の 最適解を $\left(s^{*},\left(\tau^{*}\right)^{\top}\right)^{\top}$ とおく. $s^{*} \leq 0$ のとき, $\left(t,\left(\tau^{*}\right)^{\top}\right)^{\top}$ は問題 $(22)$ の実行可能解であるから， $t^{*} \geq t$ が成り立つ.また， $s^{*}>0$ のとき， $t^{*}<t$ が成り立つ. そこで, 問題 (22) に対し, 二分法 ${ }^{24}$ に基づく次 のアルゴリズムを提案する. 


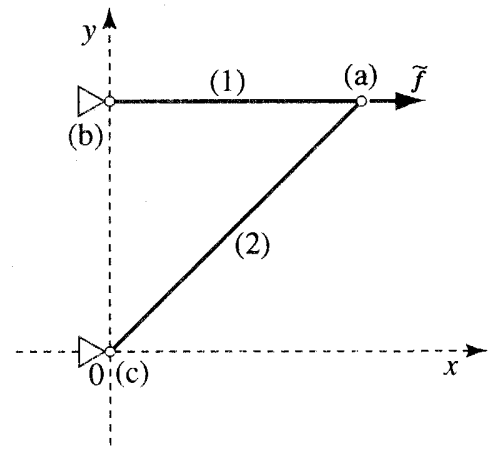

図 32 部材トラス

\section{アルゴリズム 5.2.}

Step 0: $\underline{t}^{0} \leq t^{*}, \hat{t}^{-1} \geq t^{*}, \epsilon>0$ を選び, $k:=0$ とする.

Step 1: $\bar{t}^{k}-\underline{t}^{k} \leq \epsilon$ ならば, 反復終了. それ以外は, $t:=\left(\underline{t}^{k}+\bar{t}^{k}\right) / 2$ と扔く.

Step 2: SDP 開題 (26) を解き, $s^{*}$ を求める.

Step 3: $s^{\star} \leq 0$ ならば $\underline{t}^{k+1}:=t, \bar{t}^{k+1}:=\bar{t}^{k}$, それ以外は $t^{k+1}:=t$, $t^{k+1}:=\underline{t}^{k}$ と㧍く.

Step 4: $k:=k+1$ として Step 1 .

アルゴリズム 5.2 は, $\left\lceil\log _{2}\left(\left(t^{(0}-\underline{t}^{0}\right) / \epsilon\right)\right\rceil$ 㑬の問題 (26) を解くこと で問題 (22)の大域的最適解を得る。ただし, 「p门は $p$ 以上の最小の 整数である. Step 0 において，例えば $t^{0}=0$ と選べばよい。.また， の候補としては， $a^{p}=0, p=1, \ldots, n^{\mathrm{a}}$, と㧍いた場合のロバストネス 関数などが考えられる，注意 4.2 に亦したように，このときのロバ ストネス関数は容易に求めることができる．各反復のStep 2 におい て, 問題 (26) はSDP 問題 (9) に帰着できる.ただし, $m=n^{\mathrm{c}} n^{\mathrm{d}}+1$, $n=n^{\mathrm{c}}\left(2 n^{\mathrm{d}}+1\right)$ が成り立つ. SDP 問題 (26)の大域的最適解は, 主双 対内点法を用いることで効率よく求めることができ，必要な四則演 算の回数は $m, n$ の多項式で押さえられる ${ }^{25}$. 従って，与えられた $\epsilon$ に対し，アルゴリズム 5.2 が収束するまでに要する四則演算の回数 は $n^{\mathrm{c}}, n^{\mathrm{d}}$ の多項式で押さえられる。これは，トラスの自由度や制約 条件(4)の次元が大きくなつた場合にも，計算時間が急激に増える ことはないこと表しているため，重要である。

\section{6 例題}

アルゴリズム 5.2 を用いて，種々のトラスのロバストネス関数を 求める.アルゴリズム 5.2 の Step 2 では，SDP問題に対する主双対 内点法の実装である SeDuMi Ver. $1.05^{26}$ を用いて問題 (26) を解く. 数值実験には Pentium M (1.5GHz：1GB メモリ) および MATLAB Ver. 6.5.1 30 を用いる.

以下では，問題の籣略化のために座屈の影響を考慮せず，(3)で 表されるように引張と圧縮で同じ限界値 $\sigma_{i}^{\mathrm{c}}$ を設定する. しかし, 双 方に異なる限界値を設定しても，応力制約を(4) の形式に書き直す ことで，同様の取り扱いが可能である.

\subsection{2 部材トラス}

図 3 に示す 2 部材トラスを考える．無応力状態にお知る部材 (1) および (2)の長さは，それぞれ $100 \mathrm{~cm}$ および $100 \sqrt{2} \mathrm{~cm}$ である. 節 点 (b), (c) はピン支持されており, $n^{\mathrm{d}}=2, n^{\mathrm{m}}=2$ である. 部材断面積 および外力の公称值を $\widetilde{\boldsymbol{a}}=(20.0,40.0)^{\top} \mathrm{cm}^{2}$ および $\widetilde{f}=(98.0,0)^{\top} \mathrm{kN}$

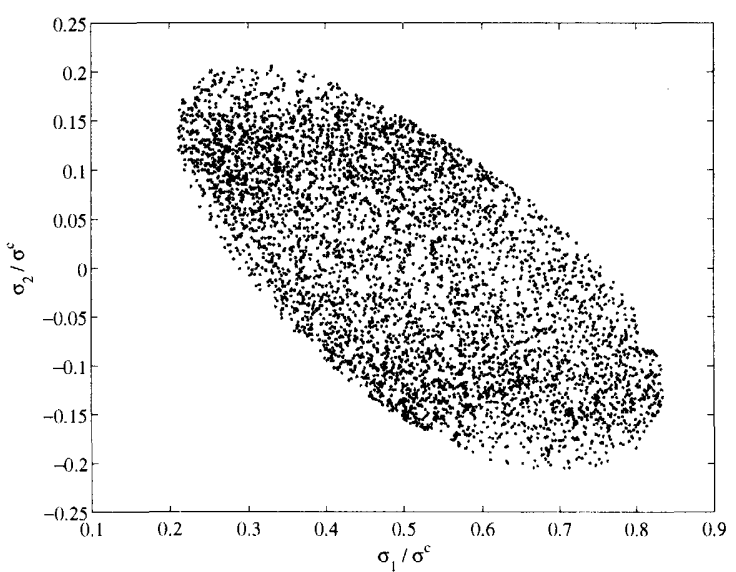

図 4 (19), (20), (27) および $\alpha=4.08$ を満たすランダムに生成され た とに対する 2 部材トラスの部材応力

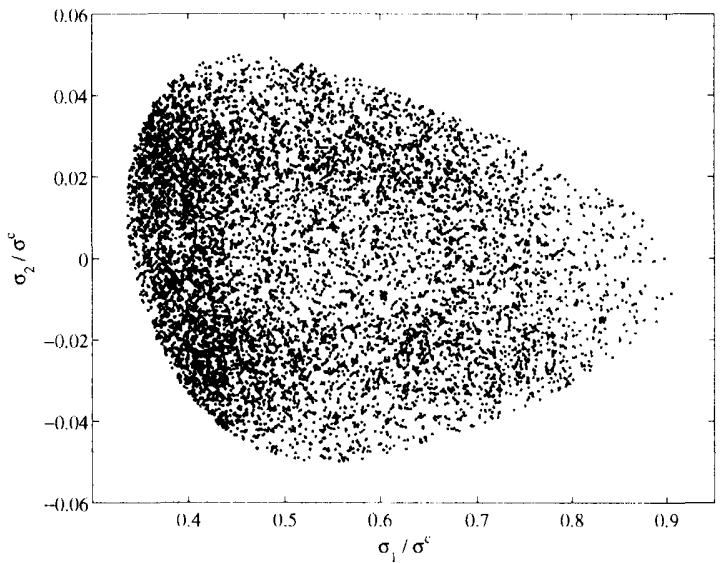

図 5 (19), (20), (28) および $\alpha=0.8944$ を満たすランダムに生成さ れた にに対する 2 部材トラスの部材応力

で与える.さらに, $\sigma^{\mathrm{c}}:=\sigma_{i}^{\mathrm{c}}=98.0 \mathrm{MPa}, i=1,2$, と扔いて, 各部材 の応力制約(3) を考慮する.

部材断面積と外力の不確定性を表す集合 $\mathcal{T}$ が(19), (20) および

$$
\begin{aligned}
& a^{1}=1.0 \mathrm{~cm}^{2}, \quad a^{2}=2.0 \mathrm{~cm}^{2}, \\
& f^{1}=(9.8,0)^{\top} \mathrm{kN}, \quad f^{2}=(0,9.8)^{\top} \mathrm{kN}
\end{aligned}
$$

で与えられるとする。ただ,$n^{\mathrm{a}}=n^{\mathrm{f}}=2$ である. $\epsilon=10^{-4}$ と おくと，アルゴリズム 5.2 によりロバストネス関数の下界として $\widehat{\alpha}\left(\boldsymbol{a}, \sigma^{\mathrm{c}}\right) \geq 4.08$ が得られる.この結果を検証するため, $\alpha=4.08$ と おき，(19),(20) を満たす $\zeta$ を考える. 図 4 に，ランダムに作られた $\zeta \in Z(4.08)$ に対応する $\left(\sigma_{1} / \sigma^{\mathrm{c}}, \sigma_{2} / \sigma^{\mathrm{c}}\right)^{\top}$ を示す. 図 4 に示される全 ての場合において，制約条件(3) が満たされている. 即ち， $\alpha \leq 4.08$ の範囲での部材断面積および外力の変動に対しては，このトラスは 応力制約を満足することが保証される。このように， ち保守的な近似值が得られたことが分かる.

次に，(27)の代わりに，断面積が外力に対して相対的に大きな変 動を持つ場合として

$$
\begin{aligned}
& a^{1}=10.0 \mathrm{~cm}^{2}, \quad a^{2}=20.0 \mathrm{~cm}^{2}, \\
& f^{1}=(9.8,0)^{\top} \mathrm{kN}, \quad f^{2}=(0,9.8)^{\top} \mathrm{kN}
\end{aligned}
$$

を仮定する.アルゴリズム 5.2 を用いると，ロバストネス関数の下 界として $\widehat{\alpha}\left(\boldsymbol{a}, \boldsymbol{\sigma}^{c}\right) \geq 0.8944$ が得られる. 図 5 は, ランダムに作ら 


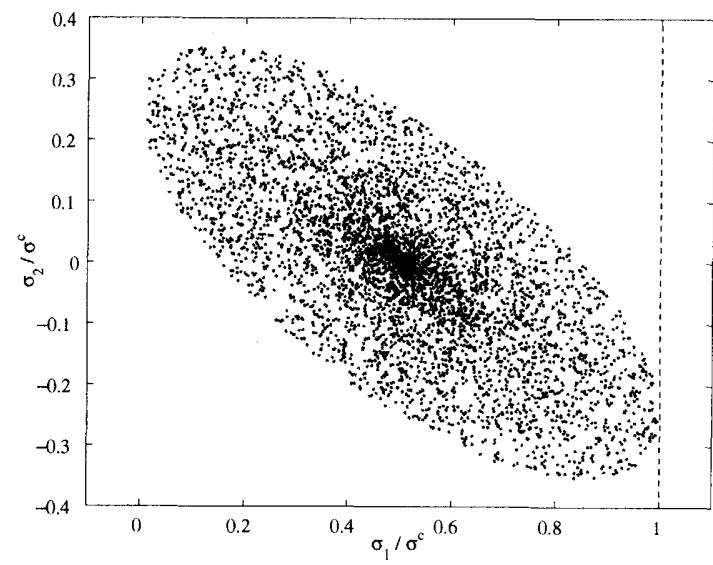

図 6 (19), (20), (29) および $\alpha=\widehat{\alpha}$ を満たすランダムに生成された $\zeta$ に対する 2 部材トラスの部材応力

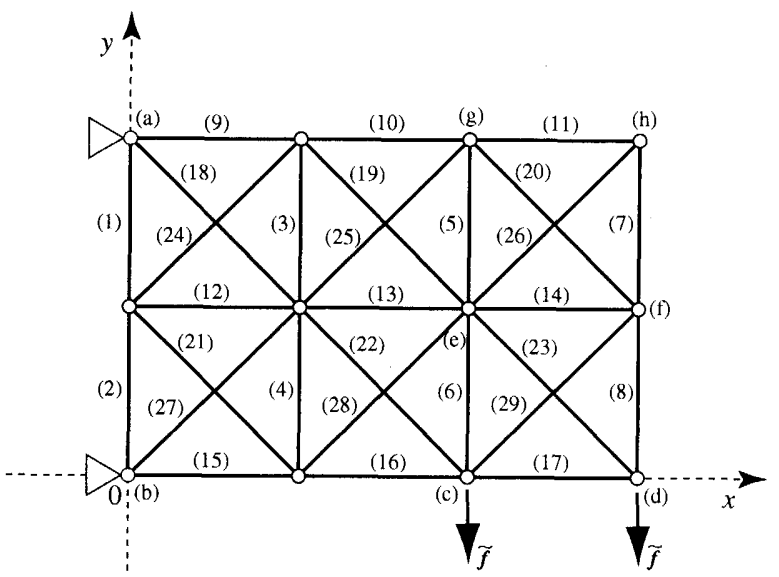

図 729 部材トラス

れた $\zeta \in \mathcal{Z}(0.8944)$ に対応する $\left(\sigma_{1} / \sigma^{\mathrm{c}}, \sigma_{2} / \sigma^{\mathrm{c}}\right)^{\top}$ を表す。図 5 に示 される全ての場合において, 制約条件(3) が満たされていることが 分かる. また，(28) は(27) と比べ, 断面積の変動が外力の変動に対 して相対的に大きいことを意味しており，得られた $\widehat{\alpha}\left(\widetilde{a}, \sigma^{\mathrm{c}}\right)$ の下界 は(27)の場合の 4.08 よりも小さい.

比較のため, 断面積 $\boldsymbol{a}$ が不確定性を持たない場合を考える. 即 ち, (19),(20) において

$$
n^{\mathrm{a}}=0, \quad f^{1}=(9.8,0)^{\top} \mathrm{kN}, \quad f^{2}=(0,9.8)^{\top} \mathrm{kN}
$$

を仮定する．このとき，注意 4.2 に示した手法により，ロバストネ 不関数として $\widehat{\alpha}\left(\vec{a}, \sigma^{c}\right)=7.0711$ が得られる，図 6 は, ランダムに作 られた $\zeta \in \mathcal{Z}(\widehat{\alpha})$ に対応する $\left(\sigma_{1} / \sigma^{\mathrm{c}}, \sigma_{2} / \sigma^{\mathrm{c}}\right)^{\top}$ を表す. 図 6 に示す全 ての場合に, 制約条件(3)が満たされている. また，ロバストネス関

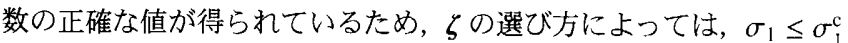
がアクティブとなり得ることが分かる.ささらに, 条件(29) は断面積 が不確定性を有さないため, 条件(27) や条件(28)の場合に比べて得 られたロバストネス関数の值は大きい.

\subsection{9 部材トラス}

図 7 に示す 29 部材トラスを考える. トラスの $x$ 軸および $y$ 軸方 向の部材の長さは，ともに $50.0 \mathrm{~cm}$ である. また, 節点 (a), (b) は ピン支持されており, $n^{\mathrm{d}}=20, n^{\mathrm{m}}=29$ である.

外力の公称值 $\widetilde{f}$ とて, 節点 (c) および (d) に $(0,-9.8) \mathrm{kN}$ を作

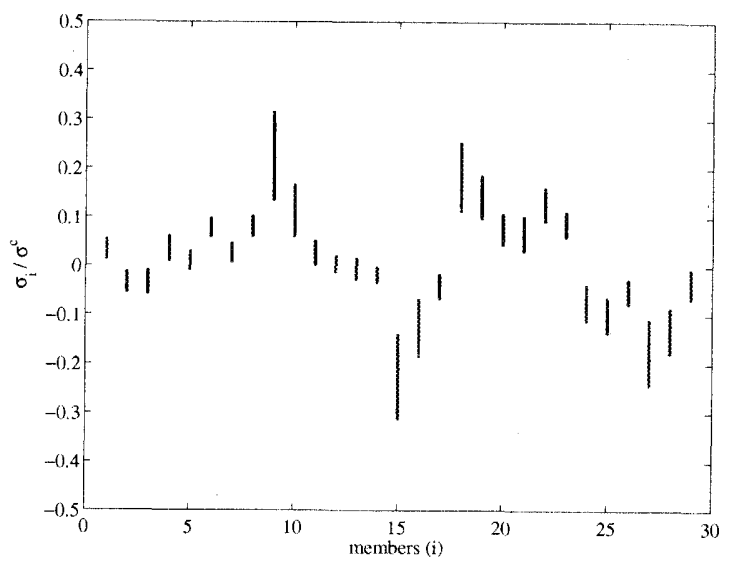

図 8 (19), (20), (30), (31), (32) および $\alpha=2.4578$ を満たすうンダ ムに生成された $\zeta$ に対する 29 部材トラスの部材応力

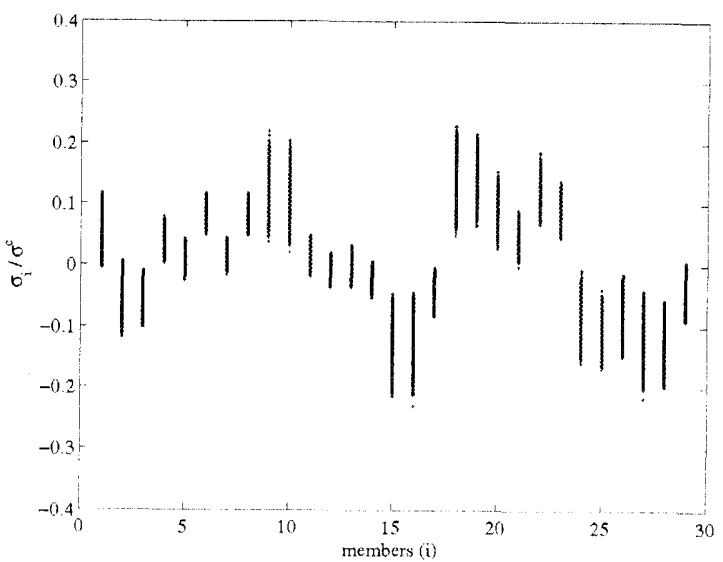

図 9 (19), (20), (31), (32), (34) および $\alpha=4.0534$ を満たすランダ ムに生成された とに対する 29 部材トラスの部材応力

用させる．また，部材断面積の公称値を

$$
\widetilde{a}_{i}=40.0 \mathrm{~cm}^{2}, \quad i=1, \ldots, n^{\mathrm{m}}
$$

とする. さらに, $\sigma^{\mathrm{c}}:=\sigma_{i}^{\mathrm{c}}=9.8 \times 10^{2} \mathrm{MPa}, i=1, \ldots, n^{\mathrm{m}}$, とおいて, 各部材の応力制約 $(3)$ を考慮する.

まず, $n^{\mathrm{a}}=n^{\mathrm{m}}, n^{\mathrm{f}}=n^{\mathrm{d}}$ とおき, 集合 $\mathcal{T}$ が(19),(20) および

$$
\begin{aligned}
& a^{p}=2.0 \mathrm{~cm}^{2}, \quad p=1, \ldots, n^{\mathrm{m}}, \\
& f_{j}^{p}=\left\{\begin{array}{ll}
1.96 \mathrm{kN}, & \text { if } j=p, \\
0, & \text { if } j \neq p,
\end{array} \quad p=1, \ldots, n^{\mathrm{d}}\right.
\end{aligned}
$$

で与えられる場合を考える. 即ち, 全ての節点に任意の方向の不確定 外力が作用し得る. $\vec{t}^{-0}=20.0, \underline{t}^{0}=0.0, \epsilon=10^{-3}$ とおき, アルゴリズ ム 5.2 を用いると，ロバストネス関数の下界として $\widehat{\alpha}\left(\boldsymbol{a}, \sigma^{c}\right) \geq 2.4578$ が得られる.ただし，アルゴリズム 5.2 が収束までに要した反復回 数は 15 回である. 各反復の Step 2 において SDP 問題 (26) を解く ために要した CPU 時間の平均値は 6.57 秒, 標準偏差は 0.68 秒で ある、また, SDP 問題 (26) のサイズは $m=581, n=1189$ である.

この結果を検証するため, $\alpha=2.4578$ とおき, (19), (20) を満た すとを考光る. 図 8 は, ランダムに作られた $\zeta \in Z(2.4578)$ に対し, 横軸に部材番号 $i$, 縦軸に無次元化応力 $\sigma_{i} / \sigma_{i}^{\mathrm{c}}$ を示したものである. 図 8 に示される全ての場合において, 制約条件(3) が満たされてい 
る. 即ち, $\alpha \leq 2.4578$ の範囲の変動に対しては, このトラスは応力 制約を満足することが保証される.

次に, $n^{\mathrm{f}}=12$ とおき, 節点 $(\mathrm{c})-(\mathrm{h})$ のみに対して $f^{p}$ を(32) と同 様に定義する. 従って, その他の節点には外力は作用しない.この とき，アルゴリズム 5.2 を用いて得られる $\widehat{\alpha}\left(\boldsymbol{a}, \sigma^{\mathfrak{c}}\right)$ の下界は 2.6418 である. (31), (32) を用いた場合よりも外力の不確定性の自由度が小 さいので，ロバストネス関数が大きいことが分かる.

$\mathcal{T}$ の定義(19) において $a^{p}$ および $f^{p}$ を適当に選べば, 部材断面 積と外力の相対的な不確定性の大きさを変化させることができる. 例えば, (31)の代わりに, 部材断面積の不確定性を

$$
a^{p}=0.2 \mathrm{~cm}^{2}, \quad p=1, \ldots, n^{\mathrm{m}}
$$

で表し，これと(32) を用いてて を定義する．このときアルゴリズ ム 5.2 を用いて得られる $\widehat{\alpha}\left(\vec{a}, \sigma^{\mathfrak{c}}\right)$ の下界は 3.0534 である.

最後に, (30)の代わりに, 部材断面積の公称值を

$$
\widetilde{a}_{i}= \begin{cases}15 \mathrm{~cm}^{2}, & i=9,15,18,27, \\ 65 \mathrm{~cm}^{2}, & i=1,2,24,26, \\ 40 \mathrm{~cm}^{2}, & \text { otherwise. }\end{cases}
$$

とおき，(31)，(32) を用いて $\mathcal{T}$ を定義する。アルゴリズム 5.2 を用 いて得られる $\widehat{\alpha}\left(\boldsymbol{a}, \boldsymbol{\sigma}^{\mathrm{c}}\right)$ の下界は 4.0534 である. 従って, 四 8 におい て态力の絶対值が大きくなり得る部材の断面積を増やすことで，口 バストネス関数を大きくすることができることが例証された。网 9 は，ランダムに作られた $\zeta \in Z(4.0534)$ に刘忘する部材心力在示す。 アルゴリズム 5.2 を朋いて得られる解は，ロバストネス関数の下界 であり，一般には正解ではない，従って，制約条件(3)のいず执 がアクティブとなる場命は戍9には現れていない。

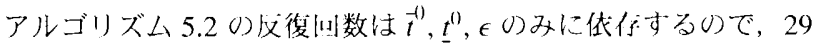
部材トラスの全ての例題に拀いて同じである. また，各必復の Step 2 に执いて解くSDP問題 (26)の次元も同じであるので, アルゴリズ ム 5.2 が要する补算時間はいずれり例題でも同じ程度である。

\section{7 結論}

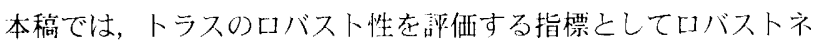
又関数を考え，その近似解を効率よく得る手法を提案した。

トラスの部材剛性および外力がインフォ・ギャップ不確定性モデ ル15 に基づく不確定性を有するこ上を仮定し，応力制約に関する卜 ラスのロバストネス関数を, 半無限㖕画問題の最適俌として定式化 した，特に，不確定性集合が不確定性パラメ一夕のノルムに関するる 不等式制約を用いて定義される場合について考察した。

次に, 非凸型 2 次計画問題に対する半正定值計画緩和を用いるこ とで, 半無限計画問題の下界が有限次元の数理計画問題を解くこと により求められることを示した。得られた問題が淮凸計画問題であ ることを示し, 半正定值計画問題を繰り返し解くことで大域的最適 解を得るアルゴリズムを提案した。このアルゴリズムが収束するま でに要する四則演算の回数は, 構造物の自由度と不確定性パラメー 夕の次元の多項式で押さえられる. 従って, 本手法はロバストネス 関数に対して妥当な計算複雑度を持つ近似アルゴリズムである.

種々の数値例題を通し, 本手法がロバストネス関数の妥当な下界, 即ち保守的な近似値を与えることを示した.

\section{参考文献}

1) Tsompanakis, Y. and Papadrakakis, M., Large-scale reliability-based structural optimization, Struct. Multidisc. Optim., 26 (2004) 429-440.
2) Qu, X. and Haftka, T., Reliability-based design optimization of stiffened panels, Proc. 4th Int. Sym. on Uncertainty Modeling and Analysis (ISUMA'03), College Park, Maryland, 2003.

3) Choi, K.K., Tu, J. and Park, Y.H., Extensions of design potential concept for reliability-based design optimization to nonsmooth and extreme cases, Struct. Multidisc. Optim., 22 (2001) 335-350.

4) Kharmanda, G., Olhoff, N., Mohamed, A. and Lemaire, M., Reliabilitybased topology optimization, Struct. Multidisc. Optim., 26 (2004) 295 307.

5) Doltsinis, I. and Kang, Z., Robust design of structures using optimization methods, Comput. Methods Appl. Mech. Engrg., 193 (2004) 22212237.

6) Ben-Tal, A. and Nemirovski, A., Robust truss topology optimization via semidefinite programming, SIAM J. Optim., 7 (1997) 991-1016.

7) Pantelides, C.P. and Ganzerli, S., Design of trusses under uncertain loads using convex models, J. Struct. Engrg. (ASCE), 124 (1998) 318 329.

8) Han, J.S. and Kwak, B.M., Robust optimization using a gradient index: MEMS applications, to appear in Struct. Multidisc. Optim.

9) 曽我部博之, 非線形感度によるロバスト性を考慮した平面骨組の最 適驾性設計, 日本建築学会構造系論文集, 556 (2002) 63-69.

10) Ben-Haim, Y. and Elishakoff, I., Convex Models of Uncertainty in Applied Mechanics, Elsevier: New York, NY, 1990.

11) Ben-Tal, A. and Nemirovski, A., Robust optimization - methodology and applications, Math. Programming, $\mathbf{B 9 2}$ (2002) 453-480.

12) Ben-Tal, A. and Nemirovski, A., Lectures on Modern Convex Optimization: Analysis, Algorithms, and Engineering Applications, SIAM: Philadelphia, PA, 2001.

13) Calafiore, G. and El Ghaoui, L., Ellipsoidal bounds for uncertain linear equations and dynamical systems, Automatica, 40 (2004) 773-787.

14) Wolkowicz, H., Saigal, R. and Vandenberghe, L. (eds.), Handbook of Semidefinite Programming - . Theory, Algorithms, and Applications, Kluwer Academic Publishers: Dordrecht, The Netherlands. 2000.

15) Ben-Haim, Y., Information-gap Decision Theory, Academic Press: London, UK. 2001.

16）竹脇出，不確定性を有する構造物のロバス卜性の非確率的評価法, 日 本建築学会構造系論文集, 581 (2004) 55-61

17) Kanno, Y. and Takewaki, I., Direct evaluation of robustness functions of trusses associated with stress constraints, $B G E$ Research Report 04-03, Building Geoenvironment Engineering Laboratory, Kyoto University, Japan, June 2004; available at: http://www.archi.kyotou. ac.jp/bge/RR/.

18) Ito, S., Liu, Y. and Teo, K.L., A dual parameterization method for convex semi-infinite programming, Annals of Operations Research, $\mathbf{9 8}$ (2000) 189-213.

19）占川暢夋，ロコバストネ久を最大化する最適設計，第 6 回最適化シン ポジウム講演論文集, 日本機械学会, pp. 269-272, 2004.

20) Rohn, J., Overestimations in bounding solutions of perturbed linear equations, Linear Algebra and its Applications, 262 (1997) 55-65.

21) 久保幹雄,『組合せ最適化とアルゴリズム』, 共立出版, 2000.

22) Gromicho, J.A.S., Quasiconvex Optimization and Location Theory, Kluwer: Dordrecht, The Netherlands, 1998.

23) Fujie, T. and Kojima, M., Semidefinite programming relaxation for nonconvex quadratic programs, Journal of Global Optimization, 10 (1997) 367-380.

24) Boyd, S. and Vandenberghe, L., Convex Optimization, Cambridge University Press: Cambridge, UK, 2004.

25) 小島政和, 土谷隆, 水野眞治, 矢部博, 『内点法』, 朝倉書店, 2001.

26) Sturm, J.F., Using SeDuMi 1.02, a MATLAB toolbox for optimization over symmetric cones, Optimization Methods and Software, 11/12 (1999) 625-653.

27) Ohsaki, M., Fujisawa, K., Katoh, N. and Kanno, Y., Semi-definite programming for topology optimization of truss under multiple eigenvalue constraints, Comput. Meth. Appl. Mech. Engrg., 180 (1999) 203-217.

28) Kanno, Y., Ohsaki, M. and Katoh, N., Sequential semidefinite programming for optimization of framed structures under multimodal buckling constraints, International Journal of Structural Stability and Dynamics, 1 (2001) 585-602.

29）福島雅夫，『非線形最適化の基礎』，朝倉書店, 2001.

30) The MathWorks, Inc., Using MATLAB, The MathWorks, Inc.: Natick, MA, 2002 